\section{Provision of remedial therapists in geriatric medicine}

No agreement has been reached about what constitutes a satisfactory norm for the remedial therapy services. In geriatric medicine recommended norms vary from 0.26 to 0.5 trained physiotherapists and from 0.27 to 0.4 trained occupational therapists per thousand population aged 65 and over, with a corresponding number of therapy aides. ${ }^{1-4}$

In the light of the rapid increase in the numbers of very old people we thought it important to assess the present provision of remedial therapists in geriatric departments throughout the United Kingdom.

\section{Methods and results}

We received replies to a postal questionnaire on remedial therapist staffing from $213\left(76^{\circ}\right)$ of the 280 departments of geriatric medicine, which were responsible for $73 \%$ of the elderly (65 years and over) in the United Kingdom.

The table shows the number of remedial therapists in post and the numbers required to reach the lowest recommended norm of 0.25 trained and 0.5 total therapists (trained plus aides) per thousand people aged 65 and over. In each country the average number of therapists is well below these norms: indeed, it would require roughly 890 additional physiotherapists and 1250 occupational therapists to reach them. This would be equivalent to increases of $11 \%$ in the number of physiotherapists and of $38 \%$ in the number of occupational therapists in post in the National Health Service.

\begin{tabular}{|c|c|c|c|c|}
\hline & England & Wales & Scotland & $\begin{array}{c}\text { Northern } \\
\text { Ireland }\end{array}$ \\
\hline \multicolumn{5}{|l|}{ Population $\geqslant 65(\times 1000)$ : } \\
\hline Total population & 6997 & 423 & 711 & 187 \\
\hline $\begin{array}{l}\text { Study population } \\
\text { Study population as }{ }_{0} \text { of total }\end{array}$ & $4926 \cdot 8$ & & & \\
\hline & 70 & 76 & 90 & 73 \\
\hline \multirow{4}{*}{$\begin{array}{l}\text { Physiotherapists: } \\
\text { No trained } / 1000 \text { population* } \\
\text { Additional No required to reach } \\
0 \cdot 25 / 1000 \text { population* } \\
\text { No of unfilled posts } \\
\text { Total No in NHS } \\
\text { No of trained physiotherapists }+ \\
\text { aides } / 1000 \text { population* } \\
\text { Additional No of trained } \\
\text { physiotherapists }+ \text { aides } \\
\text { required to reach } 0 \cdot 5 / 1000 \\
\text { population } \\
\text { Occupational therapists: }\end{array}$} & $0 \cdot 140$ & $0 \cdot 153$ & $0 \cdot 166$ & $0 \cdot 163$ \\
\hline & $\begin{array}{c}770 \\
46 \\
6832\end{array}$ & $\begin{array}{c}41 \\
7 \\
356\end{array}$ & $\begin{array}{r}60 \\
4 \\
983\end{array}$ & $\begin{array}{r}16 \\
9 \\
264\end{array}$ \\
\hline & 0.237 & $0 \cdot 271$ & $0 \cdot 232$ & 0.348 \\
\hline & 1840 & 97 & 191 & 28 \\
\hline \multirow{3}{*}{$\begin{array}{l}\text { No trained/1000 population* } \\
\text { Additional No required to reach } \\
0 \cdot 25 / 1000 \text { population* } \\
\text { No of unfilled posts } \\
\text { Total No in NHS } \\
\text { No of trained occupational } \\
\text { therapists + aides } / 1000 \\
\text { population* }\end{array}$} & 0.098 & 0.079 & $0 \cdot 113$ & $0 \cdot 148$ \\
\hline & $\begin{array}{l}1064 \\
110 \\
2718\end{array}$ & $\begin{array}{c}72 \\
13 \\
142\end{array}$ & $\begin{array}{c}97 \\
7 \\
348\end{array}$ & $\begin{array}{r}19 \\
2 \\
151\end{array}$ \\
\hline & & & & \\
\hline \multirow{2}{*}{$\begin{array}{l}\text { No of trained occupational } \\
\text { therapists }+ \text { aides required to } \\
\text { reach } 0 \cdot 5 / 1000 \text { population* }\end{array}$} & 0.215 & $0 \cdot 219$ & $0 \cdot 217$ & 0.320 \\
\hline & 1994 & 119 & 201 & 34 \\
\hline
\end{tabular}

NHS = National Health Service

$* 1000$ people aged 65 and over.

\section{Comment}

These figures are too large to be solved simply by the provision of extra finance. Even within the departments studied 66 physiotherapy and 132 occupational therapy posts remained unfilled though funded. The problem is the shortage of therapists. To achieve the minimum recommended norms within the next 10 years another $80-100$ physiotherapists and occupational therapists would have to be trained each year to supply geriatric medicine alone. This would require the establishment of new training colleges.

As such increases will not be achieved some other way must be found to meet the rehabilitation needs of the community. The table shows that there is also a shortage of therapy aides, which means that untrained helpers are not being used to compensate for the unfilled posts. It would not be desirable, however, for patient management to be left to untrained staff.

One approach would be for some nurses to take more responsibility for active rehabilitation, though they now receive little training in this. Therapists often complain that their work is "undone" by nursing staff through lack of knowledge and unduly custodial attitudes. In successful units nurses continue the process of rehabilitation throughout the day. That they should receive an appropriate training in rehabilitation seems reasonable. We propose that a certificate of rehabilitation nursing be established as a postbasic qualification, which would train nurses in all aspects of rehabilitation. We would hope that in wards in which a high degree of rehabilitation is necessary the nursing staff would have this certificate. These nurses would be expected to supervise the basic mobilisation and activities of daily living of the patients, thereby allowing therapists to concentrate on more complex and specialised techniques. Patients would benefit from a better organised and continuous programme of rehabilitation. As all specialties, including community care, have similar staffing problems, the training of the rehabilitation nurse should cover all age groups and specialties.

Therapists are unlikely to consider that nurses can carry out functions requiring skills that have taken the therapists many years of specialist training to acquire, and we would support this view. Our concern is to supplement the work of therapists and provide 24 hour rehabilitation by training some nurses to assist in basic rehabilitation. Therapists and nurses could then use their skills to better effect.

We are grateful to the King Edward's Hospital Fund for financial support, and to our colleagues in geriatric medicine for responding to our questionnaire.

1 BMA Board of Science and Education. Report of working party on care of the elderly. London: BMA, 1976 .

2 Wessex Regional Hospital Board. Report of working party on care of the elderly. Winchester: Wessex Regional Hospital Board, 1972.

3 British Geriatrics Society. Report on rehabilitation services. London: British Geriatrics Society, 1974

College of Occupational Therapists. Recommended minimum standards for occupational therapy staff: patient ratios. London: College of Occupational Therapists,

Accepted 27 fune 1984)

University Hospital of South Manchester, Manchester M20 8LR

KEITH ANDREWS, $M D, M R C P$, consultant geriatrician

J C BROCKLEHURST, MD, FRCP, professor of geriatric medicine

Correspondence to: Dr K Andrews.

\section{Pituitary infarction and development of the empty sella syndrome after gastrointestinal haemorrhage}

Spontaneous destruction of the pituitary may occur after haemorrhage into the gland (usually into a tumour) as in pituitary apoplexy or by infarction after severe hypotension (usually in an enlarged gland) such as in postpartum haemorrhage or Sheehan's syndrome. We describe a patient with acromegaly who sustained spontaneous infarction of her tumour with resolution of her acromegaly after a massive gastrointestinal haemorrhage. She also developed the empty sella syndrome with intrasellar arachnoid herniation of cerebrospinal fluid.

\section{Case report}

A 48 year old woman presented with a history of shortness of breath, lethargy, amenorrhoea of two years' duration, acral enlargement, and a hoarse voice. She had typical physical features of acromegaly and congestive heart failure. Investigations showed a raised basal growth hormone concentration of $70 \mathrm{mU} / \mathrm{l}$, which failed to decrease after administration of $100 \mathrm{~g}$ oral glucose. Glucose tolerance was normal. Computed tomography (EMI scanner) showed an enlarged pituitary fossa within which was a high attenuation mass that was enhanced after injection of contrast.

Despite treatment with diuretics she developed worsening right heart failure, obstructive sleep apnoea, and hypoventilation and underwent tracheostomy. Two days before planned transsphenoidal hypophysectomy she collapsed after a massive gastrointestinal haemorrhage. Her blood pressure was unrecordable for 15 minutes, and she remained hypotensive with a systolic blood pressure of less than $60 \mathrm{~mm} \mathrm{Hg}$ for a further hour despite transfusion of 16 units of whole blood. She underwent emergency laparotomy, at which a bleeding duodenal ulcer was found and oversewn.

During her convalescence from this episode her acromegalic features resolved. Repeat investigations 12 weeks after her gastrointestinal bleed showed a basal growth hormone concentration of $6 \mathrm{mU} / \mathrm{l}$, which did not alter after administration of $100 \mathrm{~g}$ glucose. Repeat computed tomography (Phillips Tomoscan 310) showed no evidence of pituitary tumour, although there was thinning of the sella floor and arachnoid herniation of cerebrospinal fluid 